Fecha de recepción: abril 2020

Fecha de aceptación: mayo 2020

Versión final: junio 2020

\section{Rio Recrio: O Rio de Janeiro antigo e o novo - retratos da cidade em crônicas no \\ Instagram}

Julio Jorge Trindade Duarte ${ }^{(1)}$

Resumo: Na metade do século XIX e início do século XX, as transformações urbanas que aconteceram em metrópoles como Paris, Londres e Rio de Janeiro foram acompanhadas pelo olhar dos cronistas que vagavam pelas ruas registrando seus movimentos. Hoje, com o acesso cada vez mais difundido às redes sociais, o cidadão comum produz registros diários sobre seu entorno, formando uma cartografia visual de sua cidade. Este artigo, através da criação de um perfil no Instagram denominado "Rio Recrio", averigua relações que podem ser estabelecidas entre aqueles cronistas e os usuários da rede social, tendo como cenário as transformações urbanas do Rio de Janeiro no período conhecido como Belle Époque e o contemporâneo.

Palavras chave: Narrativa - Cidade - Instagram - Crônicas - Metrópole - Literatura.

[Resumos em espanhol e inglês na página 255]

${ }^{(1)}$ Jornalista e professor. Mestre em Mídias Criativas pela UFRJ.

\title{
A cidade como estado de espírito
}

Na virada do século XIX para o século XX, a cidade passa a figurar definitivamente no elenco das grandes questões do pensamento social, trazendo indispensáveis reflexões sobre a dinâmica entre indivíduo e sociedade e sua dialética relação. As transformações do espaço público em diversas metrópoles no período fizeram surgir um novo pensamento de natureza sociológica e antropológica que usaram a cidade como um verdadeiro laboratório para a etnografia.

A Revolução Industrial faz emergir uma sociedade profundamente marcada pela divisão do trabalho, pelo rápido crescimento populacional e pelos novos fluxos de correntes migratórias. A partir dela, como aponta Harvey (1989, p. 32), são criadas também novas condições de produção (a máquina, a fábrica, a urbanização), de circulação (os novos sistemas de transportes e comunicações) e de consumo (a ascensão dos mercados de massa, da publicidade, da moda de massas). 
Um dos marcos mais importantes para a consolidação da chamada Sociologia Urbana como ramo de estudos especializados foi, indiscutivelmente, a criação da Escola de Chicago, na década de 1910, por iniciativa de sociólogos americanos que integravam o corpo docente do Departamento de Sociologia da Universidade de Chicago, fundado pelo historiador e sociólogo Albion W. Small. O surgimento da escola está diretamente associado ao processo de expansão urbano e crescimento demográfico da cidade norte-americana no início do século XX, fruto do desenvolvimento industrial acelerado das metrópoles do meio-oeste dos Estados Unidos.

A rápida transformação humana e geográfica de Chicago trouxe como consequência uma série de problemas sociais, como o crescimento da criminalidade, bolsões de pobreza e desemprego, a dificuldade de lidar com os imigrantes e a formação de comunidades segregadas (os guetos). Esses temas (à época chamados de "patologias sociais") viriam a se tornar os principais objetos de pesquisa para os sociólogos da Escola de Chicago, que são até hoje referência para o estudo dos contextos urbanos.

Jornalista e sociólogo, Robert Ezra Park é tido como um dos grandes expoentes da Escola de Chicago. Em seu clássico artigo "A cidade: sugestões para a investigação do comportamento humano no meio urbano", publicado em 1916, Park comenta a necessidade de a cidade passar a ser pesquisada de forma antropológica, no mesmo modelo com que pesquisadores fizeram com os chamados povos primitivos.

Até o presente, a Antropologia, a ciência do homem, tem-se preocupado principalmente com o estudo dos povos primitivos. Mas o homem civilizado é um objeto de investigação igualmente interessante, e ao mesmo tempo sua vida é mais aberta à observação e ao estudo. A vida e a cultura urbanas são mais variadas, sutis e complicadas, mas os motivos fundamentais são os mesmos nos dois casos. Os mesmos pacientes métodos de observação despendidos por antropólogos tais como Boas e Lowie no estudo da vida e maneiras do índio norte-americano deveriam ser empregados ainda com maior sucesso na investigação dos costumes, crenças, práticas sociais e concepções gerais de vida que prevalecem em Little Italy, ou no baixo North Side de Chicago, ou no registro dos folkways mais sofisticados dos habitantes de Greenwich Village e da vizinhança de Washington Square em Nova York (Park, 1987, p. 28).

Para Park (1979), a cidade configura-se como um corpo de costumes e tradições que afeta indivíduos, grupos e classes sociais. $\mathrm{O}$ autor aponta a cidade como um estado de espírito que apresenta um mosaico de pequenos mundos que se tocam, mas não se interpenetram. Walter Benjamin, por su vez, vê na Paris do século XIX a cidade exemplo da modernidade burguesa. A partir da segunda metade daquele século, Georges Eugene Haussmann, o barão de Haussmann, então prefeito da capital francesa e circunvizinhanças, investido por um mandato imperial de Napoleão III, realiza uma significativa reforma na capital, praticamente destruindo a cidade velha e construindo uma nova.

Alguns fatores motivaram a modernização da capital. Um deles era evitar novos levantes revolucionários, com suas barricadas, como acontecera em dezembro de 1851, quando houve uma forte reação armada da esquerda e dos operários contra o desejo de Napoleão 
III de continuar no poder. Entre 1830 e 1848, outros sete levantes armados já haviam eclodido no centro de Paris.

Surge então a nova Paris, a cidade-luz, com a construção de largas avenidas (Champs Elysées a mais famosa delas), praças, parques, anexação dos subúrbios e construção de sistema de esgoto, mananciais e abastecimento de água tratada. Muito do que se vê hoje em Paris é fruto das transformações promovidas por Haussmann durante sua longa administração, de 1853 a 1870.

Essa nova atmosfera e conjunto de fatores propiciaram o surgimento da literatura da nascente grande cidade. As transformações do espaço urbano e suas consequentes tensões e conflitos começam a ser descritas por olhares atentos de escritores que passam a ter a cidade como "musa". A cidade torna-se ela mesmo discurso e linguagem e seus fragmentos revelam partes de um complexo todo.

\section{O Rio de Janeiro e a Belle Époque}

Se Baudelaire retratava as mudanças da modernidade em Paris, Poe, em Londres, o Rio de Janeiro também teve seus "pintores" das transformações que afetaram drasticamente a então capital da república. Espelho de uma nação que se pretendia civilizada e cosmopolita, imagem e semelhança europeia, Machado de Assis, Olavo Bilac e João do Rio, cronistas aqui selecionados, fizeram um verdadeiro - e literal- passeio sociológico pelo Rio de Janeiro à época, num mapeamento humano da cidade e de seus usos, entre as últimas décadas do século XIX e a primeiro do século XXI.

A modernização do espaço urbano no Rio de Janeiro, promovida pelos então presidente Rodrigues Alves (1902-1906), prefeito Pereira Passos (1902-1906), além de Osvaldo Cruz na Saúde Pública, vinha junto a um ideal de higienização, como acontecera em Paris. Os cortiços e as ruas estreitas mal ventiladas foram, progressivamente, dando lugar às largas avenidas, parques, jardins e imponentes palacetes. Na visão da elite burguesa, era preciso acabar com a imagem antiga da cidade velha e suja, onde moravam negros, imigrantes, malandros e a maioria da população pobre. Não à toa, Pereira Passos ficou conhecido como o prefeito "bota-abaixo".

A cidade tornava-se um verdadeiro laboratório de um projeto cujas palavras de ordem eram "moderno", "civilizado" e "parisiense". Como consequência, criou-se uma crescente separação entre os redutos dos ricos e as zonas periféricas dos pobres, justificada pela modernização do espaço público e o ideal de uma urbanidade cosmopolita. Mais do que uma reorganização geográfica e física, essas transformações viriam marcar a tradição cultural e social do Rio de Janeiro, como aponta Níncia Teixeira (2012), citando uma crônica de João do Rio.

O projeto modernizador, imposto pelo governo federal ao Rio de Janeiro, atacava a questão do saneamento e determinava uma grande encomenda de obras públicas e respectivos equipamentos. Reproduzia-se, assim, de forma periférica, as portentosas obras de Paris. Seu impacto no imaginário da cidade 
pode ser aquilatado pelo conto Dias de Fantasia no qual João do Rio conta as aventuras de um príncipe egípcio que desembarcando no Rio de Janeiro disse ter circulado por "ruas que me pareciam novas em folha, colocadas entre velhas vielas. "[...] Não demorou muito para que meus olhos dessem com um boulevard iluminado como para uma festa. Era a Avenida Central” (Teixeira, 2012, s/p).

Os cronistas narravam essa cidade que buscava romper com seu passado colonial e faziam das páginas do jornal voz para seus textos. A Gazeta de Notícias era um popular jornal para os padrões à época e destacava-se como o jornal que mais dava espaço à literatura. Em 1897, Olavo Bilac substituiria Machado de Assis, então considerado o maior escritor brasileiro, na crônica semanal, espaço de maior prestígio do periódico. Quando Bilac abandonou a função, foi justamente João do Rio quem passou a publicar a coluna.

A Belle Époque foi, portanto, contada com todos os seus conflitos, tensões sociais e contradições por meio dos cronistas da época. A própria geografia da cidade, como acontecera em Paris e outras cidades, agora favorecia os passeios do flâneur, que investigavam não só as relações sociais e urbanas, mas também a "psicologia da rua".

Percebe-se nestas narrativas uma profusão de imagens que se impõem ao exercício de narrar. A cidade vista por seus cronistas que desenvolviam a arte de flanar, seja em seus aspectos sociológicos ou psicológicos, demandava novas poéticas, onde bondes, becos e vagabundos eram protagonistas.

\section{Instagram e Imagem Contemporânea}

A origem do nome "Instagram" ajuda a entender o objetivo com que inicialmente foi criado e a legião de fãs e seguidores que conseguiu conquistar em todo o mundo. O termo instant, em inglês, era um apelido das câmeras tipo "Polaroid" (Figura 1), populares nos anos 70 e 80 , que estabeleceu o conceito de fotografia em tempo real, com as imagens sendo impressas instantaneamente. O primeiro logotipo do Instagram (Figura 2) era justamente uma alusão à antiga câmera fotográfica. Já “telegram”, de telegrama, remete ao envio com rapidez.

Uma das características marcantes e particulares do aplicativo que o fez tão bem-sucedido é que, justamente por ser exclusivamente móvel, tem como objetivo ser usado para "fotos on the go". De acordo com Lev Manovich, um dos principais estudiosos contemporâneos da cultura digital, em seu livro "Instagram and Contemporary Image" (2017), o Instagram "exemplifica a era da fotografia móvel, em oposição às plataformas anteriores em desktops, como o Flickr"." O próprio cofundador do Instagram, Kevin Systrom, em um artigo de blog, em 2013, explica o conceito inicial da plataforma.

Desde nosso lançamento em outubro de 2010, nós focamos em construir um aplicativo imples que inspirasse criatividade enquanto captura momentos diários através da lente do seu telefone móvel. Na verdade, nosso foco em cons- 


\section{Polaroid

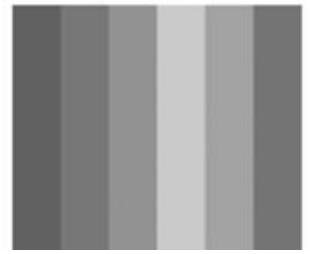

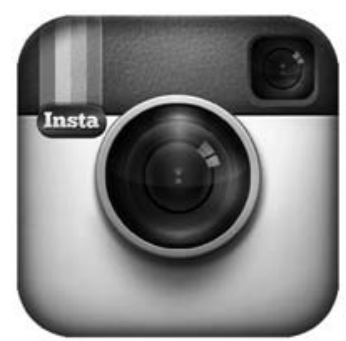

Figura 1. Site da polaroid. Figura 2. http://mundodasmarcas.blogspot.com

truir uma experiência exclusivamente móvel é uma característica que escolhermos por vários motivos. A mais importante é que o Instagram, na essência, é sobre ver e tirar fotos "on the go". Nós não oferecemos a possibilidade de subir fotos da web porque o Instagram é sobre produzir fotos "on the go", no mundo real, em tempo real' ${ }^{2}$.

Mais do que uma rede social, o Instagram cria, para Manovich (2017), uma nova estética visual, a partir do uso de seus filtros nativos para edição de fotos, além de outra característica que seria bem particular até agosto de 2015: todas as fotos eram publicadas no formato quadrado, similar à estética das câmeras Polaroid. Para o autor, essas peculiaridades ajudaram a criar não uma única cultura de uso, mas a reunir várias delas.

Olhando para a história da "fotografia" desta perspectiva, nós encontramos muitas plataformas parecidas com o Instagram, cada uma delas caracterizadas por uma combinação particular de tecnologias (...) Pense na popular Polaroid SX-70, câmera produzida entre 1972 e 1981. Ela criou a foto "instantânea" quadrada (como as fotos no Instagram entre 2010 e 2015) e criou sua própria vibrante cultura fotográfica. Ou considere a Kodachrome $35 \mathrm{~mm}$ (...) O filme tinha uma coloração diferente de outros filmes no mercado. Kodachrome também criou sua própria cultura fotográfica de famílias e amigos se reunindo para ver as imagens ${ }^{3}$.

Essas características resultam no que Manovich define como "Instagramismo", considerando a estética criada pelo Instagram, justamente por suas características particulares de uso. O autor usa o sufixo "ismo" para compará-lo a movimentos de arte modernas, como cubismo, surrealismo, entre outros. 
Eu uso o termo "Instagramismo" como uma analogia para movimentos de arte moderna, como futurismo, cubismo, surrealismo, etc. Como esses -ismos anteriores, o Instagramismo oferece sua própria visão de mundo e linguagem visual. Mas ao contrário de movimentos de arte moderna, o Instagramismo é formatado por milhões de autores conectados, participantes, no Instagram e outras redes sociais ${ }^{4}$.

A ideia de formação de conhecimento ou produção de conteúdo formatada "por milhões de autores conectados" poderia ser uma alusão ao conceito de Inteligência Coletiva (Lévy, 2011), no qual o conhecimento de um determinado tema é construído a partir do envolvimento de vários sujeitos presentes no processo de comunicação, e é esta interação que garante a compreensão ampliada do que é oferecido.

\section{Instagram e cidade}

Outra funcionalidade importante da plataforma e que serviu como fonte de pesquisa indispensável para este projeto é a possibilidade de o usuário marcar o local onde está tirando sua fotografia. O que pode parecer trivial a quem faz o registro ajuda a construir mapas visuais que podem servir para desde uma busca simples de como as pessoas postam em um restaurante ou em uma discoteca, por exemplo, a mais complexas, buscando relações e deslocamentos em cidades, países ou no mundo. Como apontam Schwartz e Halegoua, (2015, p. 1644), citados por Musse (2017), a geolocalização é também uma nova forma de representação.

A forma como representamos nós mesmos para nossas audiências online não é mais somente através de textos, vídeos ou fotos, mas também através de códigos de geolocalização, dados geográficos de visualização e mapas de padrões individuais de mobilidade (Apud Musse, 2017, p. 148).

No artigo How to Study the City on Instagram (2016), do departamento de Sociologia da Universidade de Amsterdam, os autores Boy e Uitermark introduzem métodos que podem ser usados para pesquisadores compreenderem a dinâmica urbana contemporânea urbana através desta rede social e identificar padrões e divisões. Eles próprios fazem a ressalva, no entanto, de que os usuários do Instagram escolhem as fotos que querem publicar, o que faz com a representação que fazem da cidade passe por uma curadoria.

Os estudos através de "location-based social networks" (redes sociais baseadas em localização) não começaram com o Instagram. Como aos próprios autores apontam, outras redes sociais como Twitter e Foursquare ${ }^{5}$ já eram exploradas desta forma na última década, através de tweets com geolocalização e a funcionalidade de check-in, respectivamente. Com estas análises, era possível, por exemplo, identificar quais as áreas mais utilizadas para lazer, negócios, residencial e as dinâmicas dos habitantes transitando entre estes lugares. 
Em seu estudo, Boy e Uitermark usam tanto a geolocalização quanto o conteúdo publicado pelos usuários para identificar a presença ou ausência de determinados grupos em duas cidades: Copenhagen, na Dinamarca, e Amsterdam, na Holanda. Através de uma API (Application Programming Interface) do próprio Instagram, e com o auxílio de uma ferramenta que eles próprios desenvolveram, os pesquisadores coletaram todos os check-ins em determinadas áreas urbanas destas cidades e cruzaram com a quantidade de "likes" e comentários nestas postagens em um período de 12 semanas.

Foram analisados 953.403 posts em Amsterdam e 8990.621 em Copenhagen. Mas como estavam interessados apenas nos hábitos dos moradores, e não dos turistas, consideraram apenas posts de pessoas que tinham feito publicações há 4 semanas ou mais nestas cidades, para excluir potencialmente os visitantes. Com isso, os números caíram para 442.246 e 507.445, respectivamente, o que já mostra um dado interessante: o maior número de turistas em Amsterdam.

Em seguida, os autores categorizaram grupos de atividades ou interesses com base nas imagens que postam para buscar entender quais clusters $^{6}$ frequentam determinados lugares, onde há espaços em que se cruzam ou são exclusivos de um ou outro. Estas identificações foram feitas a partir de perfis com grande número de seguidores e observando suas conexões, que chegaram a 12 grupos em Amsterdam (Tabela 1) e 16 em Copenhagen (Tabela 2)

Tabela 1. Clusters em Amsterdam.

Table 3. Additional data on Amsterdam clusters

\begin{tabular}{l|c}
\hline Cluster & Label \\
\hline AMS1 & Urban Street Culture \\
\hline AMS2 & Lifestyle Vanguard \\
\hline AMS3 & City Imagers \\
\hline AMS4 & Cultural Entrepreneurs \\
\hline AMS5 & High School Students \\
\hline AMS6 & Panclear \\
\hline AMS7 & Teenage Bon Vivants \\
\hline AMS8 & Visual Professionals \\
\hline AMS9 & Cultural Explorers \\
\hline AMS10 & Health \& Lifestyle Devotees \\
\hline AMS11 & Coffee Aficionados \\
\hline AMS12 &
\end{tabular}

Fonte: Boy e Uitermark, 2016, s/p.
Tabela 2. Clusters em Copenhagen.

Table 5. Additional data on Copenhagen clusters

\begin{tabular}{l|c|c}
\hline Cluster & Label & DIS \\
\hline $\mathrm{CPH} 1$ & Designers & 0.335 \\
\hline $\mathrm{CPH} 2$ & College Students & 0.300 \\
\hline $\mathrm{CPH} 3$ & Gymnasium Students & 0.379 \\
\hline $\mathrm{CPH} 4$ & Design \& Family & 0.315 \\
\hline $\mathrm{CPH} 5$ & Photographers & 0.305 \\
\hline $\mathrm{CPH6}$ & College Students & 0.267 \\
\hline $\mathrm{CPH7}$ & Fitness \& Nutrition & 0.366 \\
\hline $\mathrm{CPH8}$ & Teenagers & 0.504 \\
\hline $\mathrm{CPH9}$ & Gymnasium Students & 0.364 \\
\hline $\mathrm{CPH10}$ & unclear & 0.314 \\
\hline $\mathrm{CPH11}$ & Political Activists & 0.326 \\
\hline $\mathrm{CPH12}$ & Urban Street Culture & 0.359 \\
\hline $\mathrm{CPH} 13$ & High-Brown Culture & 0.337 \\
\hline $\mathrm{CPH14}$ & unclear & 0.376 \\
\hline $\mathrm{CPH15}$ & Fashion \& Marketing & 0.353 \\
\hline $\mathrm{CPH16}$ & Yoga \& Family & 0.391 \\
\hline
\end{tabular}

doi:10.1371/journal.pone.0158161.t005 
Comparando Amsterdam e Copenhagen, os autores apontam semelhanças e diferenças entre os registros dos usuários. Ambas cidades têm um grupo considerável de produtores de imagens da cidade, cuja ocupação de fotógrafo profissional ou não, é fazer fotografias das cidades onde estão situados. Em ambos, os lugares marcados como geolocalização incluem parques conhecidos, prédios e estruturas urbanas. Enquanto o cluster mais popular em Amsterdam, baseado no número de seguidores, é o "Lifestyle Vanguard”, em Copenhagen são os estudantes de high school.

Outro ponto interessante levantado pela pesquisa são os lugares em ambas as cidades que são frequentados por todos os grupos, considerados cosmopolitas, e os que são exclusivos de um ou outro, ao que denominam "parochial places". O "The Rollende Keukens", um festival de comida ao ar livre que aconteceu em um parque público da cidade no período da pesquisa, teve proporção de check-ins representativa similar em todos os clusters. Outros pontos comuns são os parques, como Vondelpark, Westpark e the Musuem Square, todos locais públicos, que funcionam como locais de encontro entre os diferentes grupos.

Os locais "paroquiais", frequentados exclusivamente por determinado grupo são fechados, como cafés, festivais de música, e até uma academia frequentada somente pelo cluster "Health and Lifestyle Devotees". Os autores apontam que a cidade é mais segregada à noite, já que os locais mais exclusivos marcados estão abertos somente no período noturno. Em Copenhagem, há constatações, por exemplo, de um festival de música que foi marcado exclusivamente pelo grupo dos designers e uma área de um shopping onde dois grupos se cruzam: os "college students" e os "gymnasium students".

Em outro estudo, dessa vez tendo somente Amsterdam como local de pesquisa, os mesmos autores investigam as desigualdades e os processos de gentrificação da capital holandesa mapeando também o Instagram, publicado no artigo "Reassembling the city through Instagram" (2017). Como a grande maioria das metrópoles urbanas, Amsterdam também vem sofrendo um processo contínuo de gentrificação nas últimas décadas e a promoção de determinados lugares e sua estetização no Instagram contribui para este fator, de acordo com eles.

Como os próprios autores afirmam, os usuários do Instagram só podem postar fotos de uma boate exclusiva se tiverem acesso à mesma. Ou só podem encher suas timelines com pratos de restaurantes renomados se puderem pagar por eles. Para aferir essas desigualdades, Boy e Ultermark coletaram 1 milhão de posts georreferenciados (Figura 3) postados na área municipal de Amsterdam durante 12 semanas entre 19 de abril e 12 de julho de 2015 que, excluídos os posts potencialmente de turistas, resultaram em 480 mil postagens, criados por mais de 30 mil usuários. Também fizeram entrevistas em profundidade com 16 usuários para entender seus usos da plataforma. 


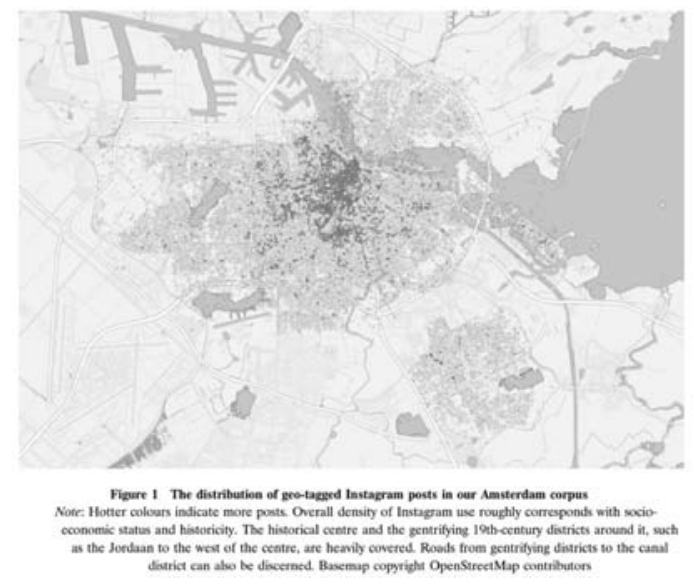

Figura 3. Distribuição de posts georreferenciados em Amsterdam. Fonte: Boy e Uitermark, 2017, s/p.

Quando o usuário faz uma postagem e ativa o serviço de geolocalização, ele quer, além de exibir sua fotografia ou vídeo, demonstrar aos outros que está ou esteve naquele lugar. Isso faz com que o Instagram, de acordo com os autores, "confirme o status ou visibilidade de determinados lugares, aumentando sua posição de destaque e confirmando sua função de motor de gentrificação. O Instagram não só alimenta, mas também reescreve desigualdades socioespaciais" (Boy e Uitermark, 2017, s/p).

A pesquisa aponta que os likes e comentários feitos na cidade através do Instagram são muito pouco distribuídos: um pequeno número de usuários recebe grande interação, enquanto a grande maioria tem níveis baixos. Em comum, essas contas são administradas por jovens, por volta de 24 anos, mulheres e que têm profissões criativas, como estilistas, designers, promotores de eventos, artistas, DJs, entre outras. Enquanto estes são de maioria absoluta branca, na zona sudeste de Amsterdam, as contas principais são de homens e mulheres negras.

Ainda segundo o estudo, menos de 12 lugares na cidade representam um quinto de todas as marcações no Instagram. O primeiro da lista, o famoso Vondelpark concentra duas vezes mais "tagueamentos" do que o segundo, um local que abriga eventos culturais, startups e bares. Os outros lugares mais marcados são boates e bares no centro da cidade, além dos museus de arte mais conhecidos.

Os autores também apontam que um dos clusters analisados consiste em homens e mulheres negros e negras, próximos aos 20 anos de idade. Suas marcações de local geralmente estão ligadas à cultura hip-hop. Apenas $6 \%$ dos posts têm a geolocalização marcada e, em sua maioria, são em Bijlmer, uma comunidade predominantemente negra na periferia de Amsterdam. Suas publicações têm grande identificação própria e local, e em suas fotos aparecem roupas de streetwear. Um dos entrevistados, morador de Ganzenhoef, zona periférica de Amsterdam diz o porquê de não registrar fotos ali. 
Se você mora em Pijp, você pode mover sua câmera em 180 graus, é mais fácil. Mas se você faz o mesmo movimento em Ganzenhoef, você vai ver uma pessoa usando crack. Tem crianças se divertindo, com certeza, jogando bola. Ou um viciado pedindo dinheiro. Ou vários caras fumando maconha. Não é realmente positivo, como as pessoas diriam ${ }^{7}$.

Boy e Ultermark (2017) concluem apontando que os feeds do Instagram são os locais para corpos atraentes, rostos bonitos, comidas saudáveis e cenários belos, montando uma cidade asséptica e longe de negatividades. A desordem, a melancolia e a desgraça não têm lugar ali, já que os usuários fazem uma acurada seleção do que postar para que tenham interação e reação dos seus seguidores. Enquanto determinados lugares são expostos massivamente na plataforma, outros permanecem periféricos ou ignorados, reproduzindo e impulsionando o status de uns e a quase negação de outros.

A pesquisa aponta, por exemplo, que um determinado cluster de pessoas de áreas mais nobres tem seis vezes mais probabilidade de postar uma foto no Instagram com a geolocalização do que no cluster de negros e negras da zona periférica da cidade. Isso sugere, segundo Boy e Ultermark, que alguns grupos têm mais poder simbólico e financeiro para remontar a cidade e o Instagram é uma ferramenta que ajuda a conseguirem isso.

Feito em Amsterdam, o interessante estudo serve de referência para posteriores análises que devem apontar ainda mais desigualdade espacial, física e virtual, em cidades da América Latina, especialmente metrópoles brasileiras como Rio de Janeiro e São Paulo.

\section{Rio Recrio: retratos da cidade antiga e contemporânea em crônicas no Instagram}

Os recursos do aplicativo, suas perspectivas estéticas e espaciais, abordados neste capítulo, serviram como referências fundamentais para a criação do "Rio Recrio". O perfil do projeto foi inaugurado no Instagram em 5 de agosto de 2017 e sua última publicação foi feita em 24 de março de 2018, totalizando 54 postagens.

A ideia inicial era fazer uma relação entre as fotografias de Marc Ferrez e, possivelmente, Augusto Malta (Figura 4), outro importante fotógrafo da época, com os novos registros dos usuários contemporâneos do Instagram, buscando semelhanças e contrastes entre as imagens. As crônicas dos autores escolhidos (Machado de Assis, João do Rio e Olavo Bilac) seriam escritas no espaço para as legendas no Instagram. No entanto, para quem visse o projeto no feed do Instagram não teria a dimensão clara entre as crônicas trabalhadas e os registros contemporâneos, já que as legendas não aparecem nesse formato de visualização e têm pouco destaque no aplicativo.

Surgiu, então, outro desafio que era o de transformar crônicas em objetos visualmente atraentes no Instagram, já que a mídia é predominantemente estética, como apontada por Manovich, Salazar e outros autores. Com isso, fez-se necessário a criação de uma identidade visual atraente, que representasse a ideia de espaço e tecnologia transmitida pelo projeto. Foi desenvolvida, junto à designer Caroline Baptista, um logotipo (Figura 

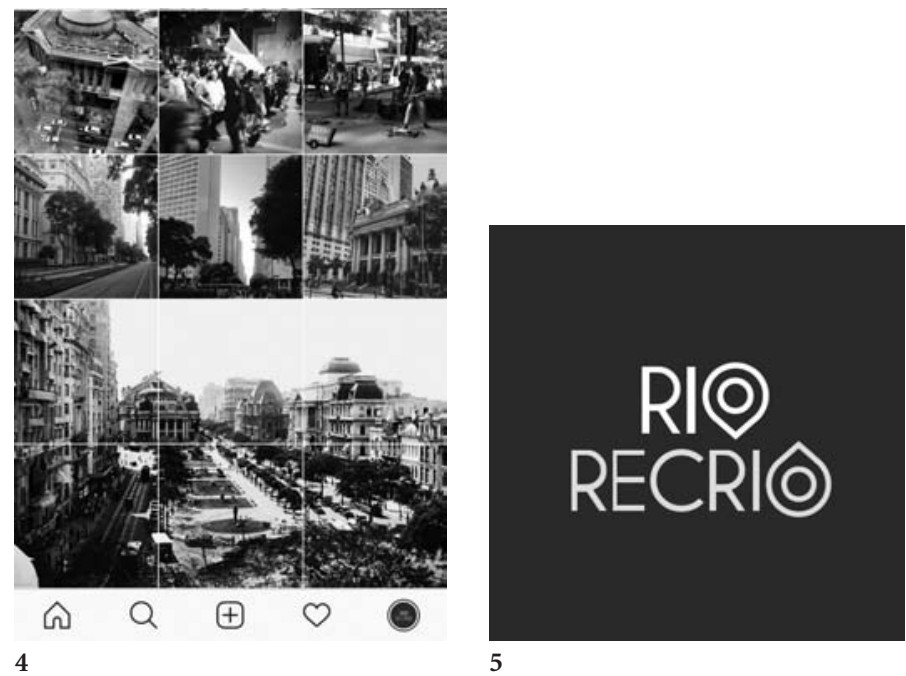

Figura 4: Primeiras publicações do perfil Rio Recrio. Fonte: Instagram, pesquisa de 22 a 26 de novembro de 2016, com fotos de diversos usuários e fotografia de Marc Ferrez (acervo IMS). Figura 5: Logo do projeto Rio Recrio. Fonte: o autor.

5) com o símbolo comumente usado para geolocalização em ambientes digitais, além de cores mais vivas, que passassem também uma mensagem de modernidade, característica do Instagram.

Com a marca, foi possível desdobrar a identidade visual também para os trechos de crônicas selecionados. Importante mencionar que os textos escolhidos tinham um recorte espacial: o centro do Rio Janeiro, por ter sido o principal local das muitas transformações da cidade no início do século XX, e também para que fosse possível fazer a relação com os registros contemporâneos da cidade. Na crônica de Olavo Bilac, por exemplo, a inauguração da então Av. Central é o tema primordial. Na de João do Rio, é a Rua do Ouvidor, e na de Machado de Assis, a chegada dos bondes elétricos.

Para a seleção das publicações do Instagram, foram usados dois métodos de coleta das fotografias, ambos manuais e disponíveis a qualquer usuário da plataforma no campo de busca: o uso da hashtag correspondente ao tema / lugar (\#vlt; \#avenidariobranco; \#ruadoouvidor) e a geolocalização utilizada pelos próprios usuários (VLT Carioca; Avenida Rio Branco; Rua do Ouvidor).

A partir dessa seleção inicial, foi feita, em seguida, uma curadoria de fotos que fossem representativas daqueles temas e excluídas outras, como selfies, pets, amigos, captioned fotos (fotos com texto na imagem), além de publicidade de vários tipos. Como reforçado o fato 


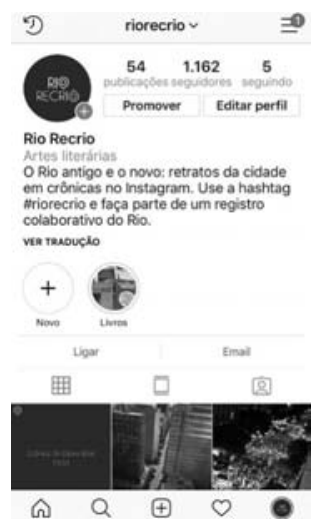

6

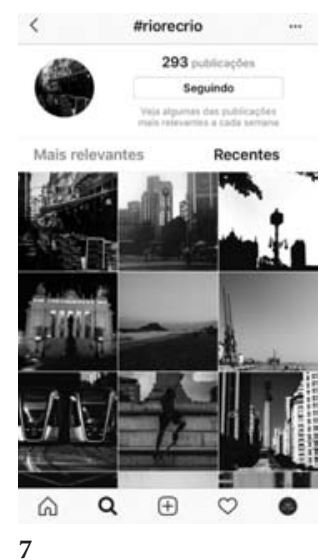

Figura 6. Perfil do Rio Recrio no Instagram. Figura 7. Fotos com a hashtag \#riorecrio.

Fonte: Instagram, pesquisa realizada entre março de 2017 e abril de 2018, com fotos de diversos usuários.

Figura 8. Perfil do Rio Recrio no Instagram com a crônica "Bondes Elétricos", de Machado de Assis, 1892. Fonte: Instagram, pesquisa de março de 2017 a abril de 2018, com fotos de diversos usuários.

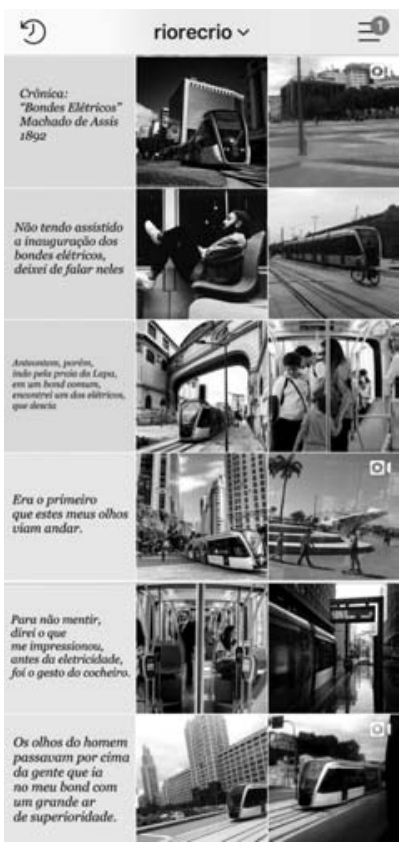

8

de, no Instagram, o componente estético ser primordial, foi dado também preferência a fotos que pudessem causar impacto e engajamento aos seguidores do projeto.

Os mais de 1.100 seguidores foram conquistados também manualmente. O perfil Rio Recrio seguia e interagia com quem postava fotos com hashtags relacionadas ao projeto, como: \#rioantigo; \#ruadoouvidor, \#avenidariobranco, \#vltcarioca, além de geolocalizações, como "rua do Ouvidor", "avenida Rio Branco" e "VLT Carioca". Muitos destes perfis se interessavam pelo projeto e seguiam de volta.

Ao encontrar o perfil, os usuários eram incentivados a participar do projeto usando a hashtag "\#riorecrio", para compor "um registro colaborativo da cidade" (Figura 6). Até 4 de dezembro de 2018, 293 publicações haviam sido feitas utilizando a hashtag (Figura 7). Muitas delas, com fotos em preto e branco, indicando que os usuários faziam relação do projeto com o Rio antigo.

A primeira crônica trabalhada foi "Bondes Elétricos", de Machado de Assis, de 1982, ainda sem a identidade visual do projeto definida. No texto, o autor escreve suas primeiras impressões sobre a chegada dos bondes elétricos, em substituição aos bondes de tração animal. À direita (Figura 8), foram postados os registros contemporâneos do VLT (veículo leve sobre trilhos)que causou forte impacto visual sobre o perímetro urbano do centro do Rio de Janeiro. 

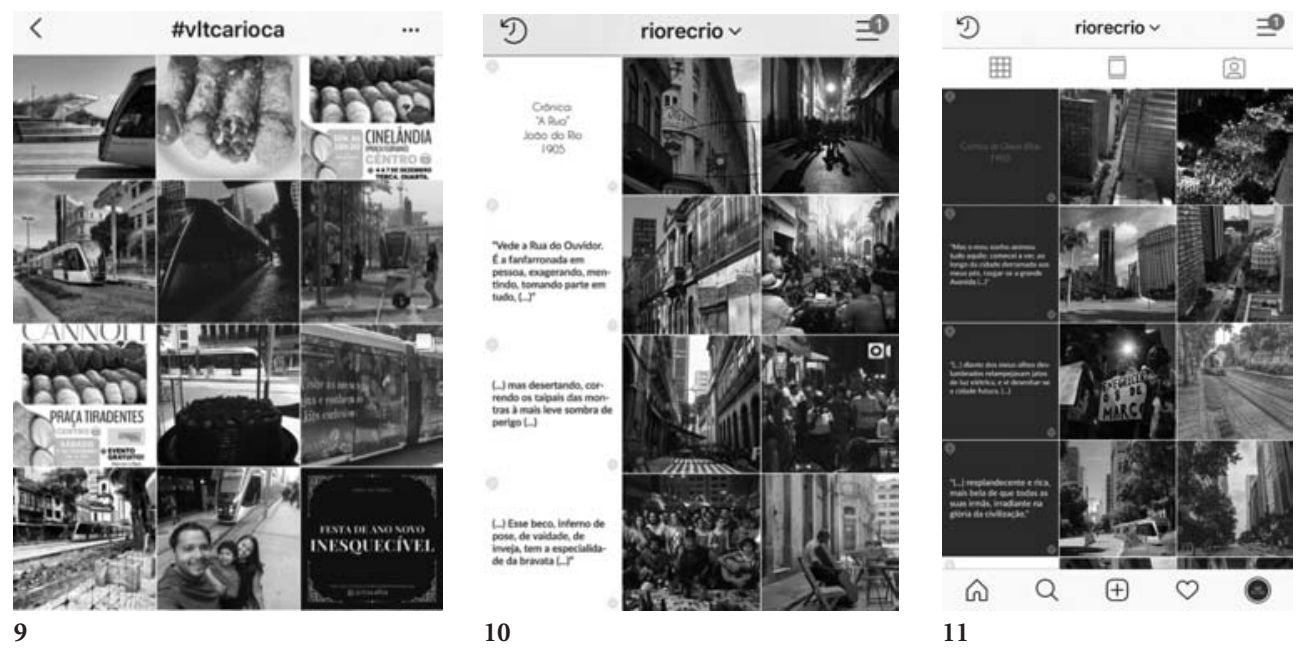

Figura 9. Fotos diversas apresentadas com a hashtag \#vltcarioca. Fonte: Instagram, pesquisa de março de 2017 a abril de 2018, com fotos de diversos usuários. Figura 10. Perfil do Rio Recrio no Instagram com a crônica "A Rua", de João do Rio (1905) e fotos relacionadas à rua do Ouvidor, tema da mesma. Fonte: Instagram, pesquisa de março de 2017 a abril de 2018, com fotos de diversos usuários. Figura 11. Perfil do Rio Recrio no Instagram com crônica de Olavo Bilac (sem nome) (1903) e fotos relacionadas à avenida Rio Branco. Fonte: Instagram, pesquisa de março de 2017 a abril de 2018, com fotos de diversos usuários.

É possível notar aqui que os bondes do VLT (Veículo Leve sobre Trilhos), através da hashtag \#vltcarioca, por exemplo, são fotografados muitas vezes em primeiro plano, valorizando sua moderna aparência e a novidade que representaram na paisagem do centro da cidade, a partir de 2016. É possível também observar as muitas selfies, que indicam que o carioca ou turista os vê como objeto de relativa admiração, e se inclui na paisagem, tornando-se parte dela (Figura 9).

No trecho da segunda crônica, "A Rua”, de 1905, João do Rio escreve suas impressões sobre a Rua do Ouvidor, à época, onde se desfilava à moda europeia, com trajes franceses. Curioso notar que hoje grande parte dos registros são fotos das rodas de samba que acontecem na Rua do Ouvidor, além das fotos que destacam o valor arquitetônico da rua (Figura 10). A terceira e, até o presente momento, última crônica trabalhada foi de Olavo Bilac (sem registro do nome da crônica), sobre seu entusiasmo com a inauguração da então Avenida Central, em 1903. Nos registros contemporâneos no Instagram, é possível observar o uso da perspectiva e ponto de fuga para demonstrar a grandiosidade e imponência da avenida, fechada para os carros, a partir de 2016. Bilac, se fotografasse a avenida talvez usasse essas representações (Figura 11).

Se observadas individualmente, podemos aferir neste projeto também a presença das três categorias sugeridas por Manovich. As que predominam, justamente por uma busca de 


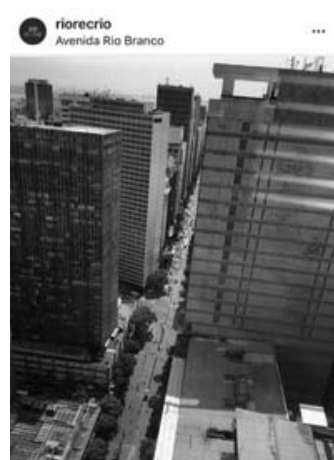

12

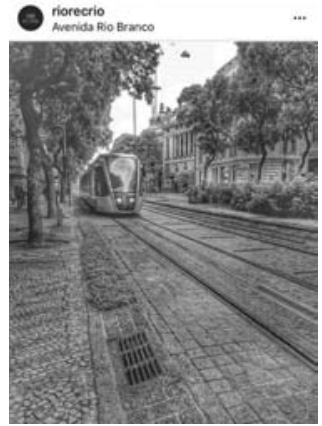

15

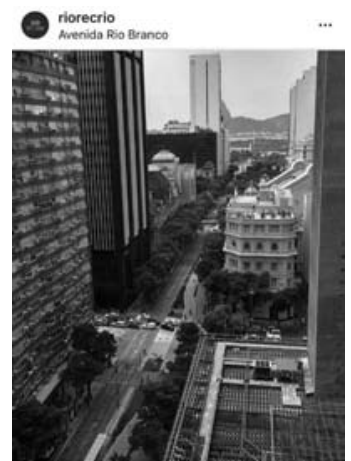

13

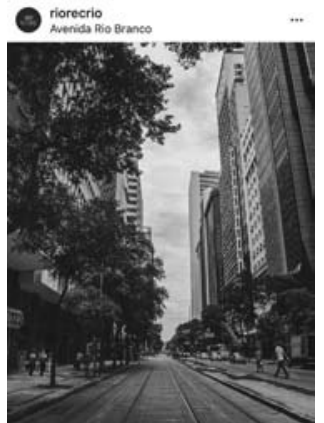

14

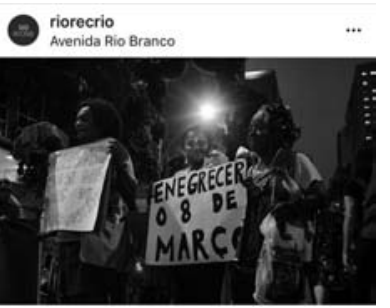

16

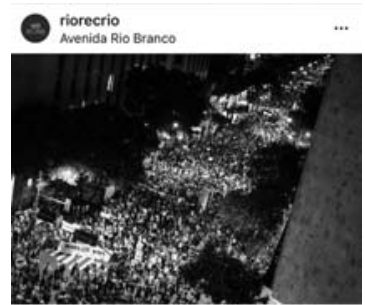

17

Figura 12. Foto do usuário @voo_alto. Figura 13. Foto do usuário @hud_fraga.

Fonte Figuras: Instagram, pesquisa de março de 2017 a abril de 2018.

Figura 14. Foto do usuário @luizcarloscg57. Figura 15. Foto do usuário@gustavolescano. Fonte: Instagram, pesquisa de março de 2017 a abril de 2018.

Figura 16: Foto do usuário: @vitorpastana. Figura 17: Foto do usuário: @lucasweglinski. Fonte Figuras: Instagram, pesquisa de março de 2017 a abril de 2018.

uma interessante composição estética, característica da rede social são as "profissionais". $\mathrm{Na}$ Avenida Rio Branco, por exemplo, são comuns as fotos que buscam técnicas como perspectiva e ponto de fuga, característicos de quando se quer dar a grande dimensão de um espaço, tanto de um ponto de vista à altura dos olhos quanto do alto de alguns edifícios, que ressaltam a ideia de grandiosidade da avenida (Figura 12, Figura 13, Figura 14, Figura 15).

Vale destacar também que no período analisado, entre março de 2017 a abril de 2018, a Avenida Rio Branco foi palco também para diversas manifestações no Rio de Janeiro, amplamente fotografadas e registradas no Instagram. Houve passeata pelo Dia Internacional da Mulher, em 8 de março, marcha em protesto ao brutal assassinato da vereadora Marielle Franco, no dia seguinte à sua morte, em 14 de março de 2018, e manifestações pela liberdade do ex-presidente Lula, por exemplo. Pode-se perceber, portanto, a avenida, por sua larga extensão, como um ponto de encontro social e político da cidade (Figuras 16 e 17). 


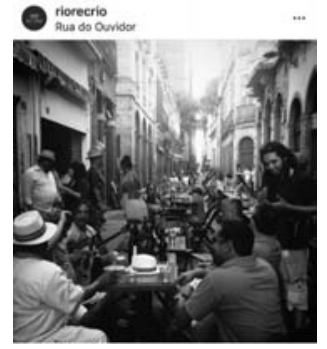

18

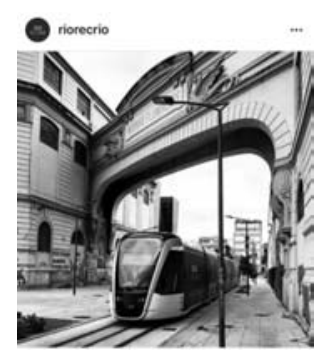

22

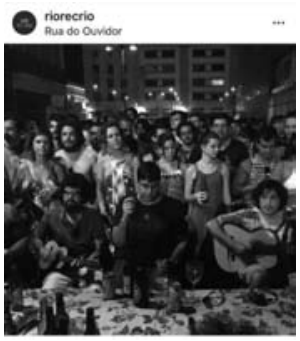

19

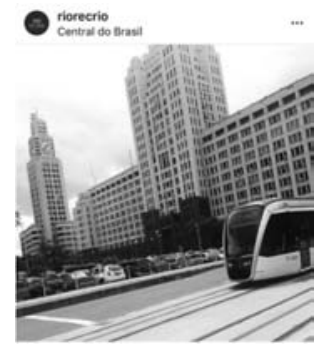

23

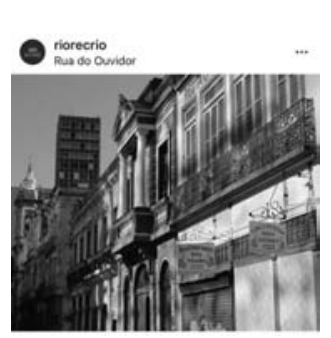

20

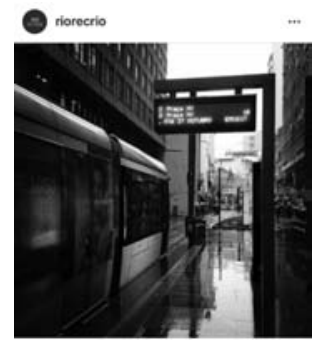

24

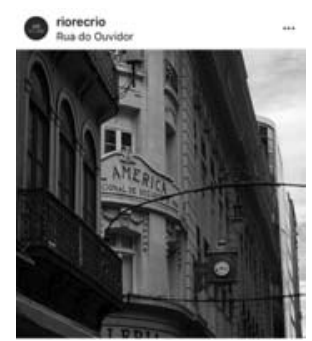

21

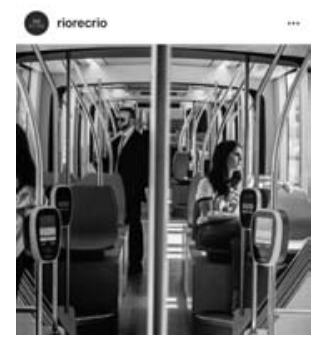

25

Figura 18. Foto do usuário @cdehollanda. Figura 19. Foto da usuária @sandrasoarescosta. Figura 20. Foto do usuário @jeff_teixeira. Figura 21. Foto do usuário @jpinon. Fonte: Instagram, pesquisa de março de 2017 a abril de 2018.

Figura 22. Foto do usuário: @raphaelhallack Figura 23. Foto do usuário: @rudson_almeida_. Figura 24. Foto do usuário @andrex_almeida. Figura 25. Foto do usuário @viniciusdantaso Fonte: Instagram, pesquisa de março de 2017 a abril de 2018.

Na Rua do Ouvidor, por sua vez, há muitos registros à noite, já que é conhecida por suas populares rodas de samba e bares, que poderiam se enquadradas na categoria de "casual”, proposta por Manovich, por terem um caráter mais de recordação do momento. Há também fotos que registram detalhes da arquitetura, com suas fachadas tradicionais e o colorido das casas, que poderiam se encaixar nas categorias professional ou "designed". (Figuras 18 e 19).

Já nas fotos do VLT, há maior diversidade de registros, já que há duas possibilidades de ponto de vista: o interno, de quem é passageiro do veículo (que pode fotografar para dentro ou para fora) (Figura 20 e Figura 21; e do externo, de quem o insere no enquadramento da fotografia. Nota-se, muitas vezes, o trem colocado em primeiro plano, tendo os imponentes edifícios do centro como pano de fundo (Figuras 22 e 23). Mas há também os registros que buscam simetria na composição de elementos e o contraste com luzes e cores, que se encaixariam possivelmente na categoria "designed" (Figuras 24 e 25). 
Se a origem grega do termo fotografia significa "escrever com a luz", podemos assumir que estes registros também escrevem - ou desenham - a cidade contemporânea. Compartilhado na rede e visto por, potencialmente, milhares de usuários locais e globais, seus enquadramentos, contrastes e luzes também moldam olhares e impressões sobre o Rio de Janeiro, como um dia também fizeram seus célebres cronistas.

\section{Notas}

1. Criado em 2004, o Flickr é um site da web de hospedagem e compartilhamento de imagens como fotografias, desenhos e ilustrações, além de permitir diferentes maneiras de organizar fotos e vídeos.

2. (SYSTROM apud MANOVICH, 2013, p. 18, (tradução nossa). Original: Since our launch in October of 2010, we've focused on building a simple app that has inspired creativity while capturing everyday moments through the lens of your mobile phone. In fact, our focus on building out a mobile-only experience is a unique path that we've chosen for many reasons, the most important of which is that Instagram, at its core, is about seeing and taking photos on-the-go. We do not offer the ability to upload from the web as Instagram is about producing photos on the go, in the real world, in realtime.

3. (MANOVICH, 2017, p. 18, tradução nossa). Original: Looking at history of "photography" from this perspective, we find many Instagramlike platforms, each characterized by a particular combination of technologies for capturing fotos (...) Think of popular Polaroid SX-70 camera produced between 1972 and 1981. It created square "instant" photo prints in one size (like photos on Instagram between 2010 and 2015) and created its own vibrant photo culture. Or consider Kodachrome 35-mm slides. (...) The film had a distinct color look different from other color films on the market. Kodachrome also created its own photo culture of families and friends gathering to see slide shows.

4. (MANOVICH, 2017, p. 18, tradução nossa). Original: I use the term "Instagramism" as an analogy to modern art movements such as futurism, cubism, surrealism etc. Like these earlier-isms, Instagramism offers its own vision of the world and its visual language. But unlike modernist art movements, Instragramism is shaped by millions of authors connected by, and participating in, Instagram and other social networks.

5. Criada em 2009, o Foursquare é uma rede geossocial e de microblogging que permite ao usuário indicar onde se encontra, e procurar por contatos seus que estejam próximo desse local.

6. Os clusters são grupos de pessoas que têm características parecidas de acordo com a segmentação proposta. O Marketing Digital, por exemplo, separa os consumidores em diferentes clusters para que sua mensagem seja mais assertiva para seus públicos-alvo.

7. BOY E UITERMARK, 2017, (tradução nossa). Original: "If you live in de Pijp, of course you can just point your camera, just like this, 180 degrees, and then move your camera. (...) Yeah, I think it's easier then. Because if you stan on the block right here, in Ganzenhoef, and you point the same camera 180 degrees, like I just told you, you will only see, like, there's a dude slanging crack over there. There's a couple of kids having fun, sure, 
kicking a ball. Or there's, like, a junkie asking people for money. Or you have a lot of guys smoking weed. It's not really positive, as people would say".

\section{Bibliografía}

Arriguci Jr, D. (1987). Enigma e comentário: ensaios sobre literatura e experiência. São Paulo: Companhia das Letras.

Assis, M. de. (1946). “A Semana” (1892-1893). In: Obras completas. São Paulo/ Rio de janeiro/ Porto Alegre: W.M. Jackson Inc. Editores. Volume I. .Obra completa (1997). Rio de Janeiro: Nova Aguilar. Volume II

Baudelaire, C. (1985). As flores do mal. 6.ed. Trad. e notas Ivan Junqueira. Rio de Janeiro: Nova Fronteira.

Paz e Terra.

. (1996). Sobre a modernidade: o pintor da vida moderna. 4 ed. Rio de Janeiro:

Barthes, R. (2003). Mitologias. Rio de Janeir: Difel.

. (1984). A Câmara Clara. Rio de Janeiro: Nova Fronteira.

. (1990). O óbvio e o obtuso: Ensaios críticos III. Rio de Janeiro : Nova Fronteira.

Benjamin, W. (1985). Sociologia. 2.ed. Trad., introd. e org. Flávio Kothe. São Paulo: Ática.

. (2009).Passagens. Tradução: Willi Bolle. Belo Horizonte: UFMG.

Berman, M. (1986). Tudo que é sólido desmancha no ar - A Aventura da modernidade. São Paulo: Cia. das Letras.

Bilac, Ol. (2006). Na Batalha das Flores. Correio Paulistano, São Paulo. In: DIMAS (2006b, v. II).

.(2011). Registro: crônicas da Belle Époque carioca. Org: Alvaro Santos Simões. Jr. Campinas (São Paulo). Editora da Unicamp.

Boy, J.y Uitermark, J. (2016). How to Study the City on Instagram. PLoS ONE 11(6): e0158161. Disponível em: https://doi.org/10.1371/journal.pone.0158161, . (2018). Reassembling the city through Instagram. Amsterdam Institute for Social Science Research (AISSR). Disponível em: https://scinapse.io/papers/2621729265.

Burke, P. (2004). Testemunha ocular: História e imagem. Bauru: EDUSC.

Calvino, Í. (2000). As cidades invisíveis. São Paulo: Cia das Letras.

Candido, A. (1982). A vida ao rés do chão, in Para gostar de ler. São Paulo: Ática. Prefácio, p. 6.

Coutinho, A. (1986). Ensaio e crônica; in: A literatura no Brasil. Rio de Janeiro; José Olympio Editora.

Eco, U. (2005). Obra Aberta: forma e indeterminação nas poéticas contemporâneas. São Paulo: Perspectiva, 2005.

Flusser, V. (2009). Filosofia da Caixa Preta. São Paulo: Relume Dumará. . (2008). O universo das imagens técnicas - Elogio da superficialidade. São Paulo: Annablume editora.

Hochman, N. Y Manovich, L. (2018). Zooming into as Instagram City: Reading the local through social media. First Monday, 2013. Disponível em: https://firstmonday.org/article/ view/4711/3698. 
Hu Yuheng, Manikonda, L. y Kambhampati, S. (2014). What we Instagram: A first analysis of Instagram Photo Content and User Types. Department of Computer Science, Arizona State University, 2014. Disponível em: http://www.public.asu.edu/ lmanikon/icwsm2014.pdf. Jenkins, H. (2008). Cultura da Convergência. São Paulo: Aleph.

Kossoy, B. (2014). Fotografia e História. São Paulo: Ateliê.

. (2016). Realidades e Ficções na Trama Fotográfica. São Paulo: Ateliê.

Lévy, P. (2011). A inteligência coletiva: por uma antropologia do ciberespaço.São Paulo: Edições Loyola.

. (1998). Cibercultura. Rio de Janeiro. Ed 34.

Machado, A. (1984). A Ilusão Especular. Introdução à fotografia. São Paulo: Editora Brasiliense.

Manguel, A. (2001). Lendo imagens: Uma história de amor e ódio. São Paulo: Companhia das Letras.

Manovich, L. (2019). Instagram and the contemporary image. Creative Commons License. Disponível em http://manovich.net/index.php/projects/instagram-and-contemporaryimage, 2017.

Magnoni, M. (2018). Dois Barretos e um Rio de Janeiro. Revista da Universidade Federal de Minas Gerais, 2013. Disponível em: https://seer.ufmg.br/index.php/revistadaufmg/ article/view/1779/1276.

Moura, F. (2007). A rua e seus olhares: A Belle Époque carioca nas crônicas de João do Rio e de Machado de Assis. Universidade Federal do Ceará. 2007. Disponível em: http://www. repositorio.ufc.br/bitstream/riufc/3426/1/2007_DIS_FSMOURA.pdf

Musee, M. (2017). Narrativas fotográficas no Instagram - autorrepresentação, identidades e novas sociabilidades. Florianópolis: Editora Insular.

Park, R. (1979). A cidade: sugestões para a investigação do comportamento humano no meio urbano. In: VELHO, Otávio Guilherme (Org.). O fenômeno urbano. 4. ed. Rio de Janeiro: Zahar, 1979. p. 13-28.

Poe, E. (1999). In: Os melhores contos de Edgar Allan Poe. trad. Oscar Mendes e Milton Amado. 3. ed. São Paulo: Globo.

Rodrigues, A. (2000). João do Rio: a cidade e o poeta - o olhar do flâneur na belle époque tropical. Rio de Janeiro: Editora FGV, 2000.

Rio, J. (2008). A alma encantadora das ruas. Rio de Janeiro. São Paulo: Companhia das Letras. - (2006). As religiões no Rio. Apresentação de João Carlos Rodrigues. Rio de Janeiro: José Olympio.

. (2001). O bebê de tarlatana rosa. In: CUNHA, Helena Parente. (Seleção). Melhores contos de João do Rio. 2 ed. São Paulo: Global.

Salazar, M. (2018). Mundo Mosaico - A estetização do cotidiano no Instagram. Curitiba: Ed. Kottler Editorial.

Santaella, L. (2004). Navegar no ciberespaço. O perfil cognitivo do leitor imersivo. São Paulo. Ed. Paulus.

Simoes, P. (2019). Algumas contribuições de Robert E. Park para o campo da comunicação. Simmel, G. (1979). A metrópole e a vida mental. In: VELHO, Otávio Guilherme (Org.). O fenômeno urbano. 4. ed. Rio de Janeiro: Zahar, 1979. p. 11-25. 
Teixeira, N. (2018). A Cidade das Letras: Machado de Assis e a Construção da Metrópole Textual. In: Revista Gláuks. 2012. Disponível em: http://www.revistaglauks.ufv.br/ arearestrita/arquivos_internos/artigos/Artigo_Nincia_C._Borges_formatado_rafa.pdf. TODOROV, T. (2013). As estruturas narrativas. Tradução: Leyla Perrone-Moisés. São Paulo: Perspectiva.

Resumen: En la mitad del siglo XIX y principios del siglo XX, las transformaciones urbanas que se produjeron en metrópolis como París, Londres y Río de Janeiro fueron acompañadas por la mirada de los cronistas que vagaban por las calles registrando sus movimientos. Hoy, con el acceso cada vez más difundido a las redes sociales, el ciudadano común produce registros diarios sobre su entorno, formando una cartografía visual de su ciudad. Este artículo, a través de la creación de un perfil en el Instagram denominado "Río Recrio", averigua relaciones que pueden ser establecidas entre aquellos cronistas y los usuarios de la red social, teniendo como escenario las transformaciones urbanas de Río de Janeiro en el período conocido como Belle Époque.

Palabras clave: Narrativa - Ciudad - Instagram - Crónica - Metrópole - Literatura.

Abstract: In the middle of the nineteenth century and the beginning of the twentieth century, the urban transformations that took place in metropolises like Paris, London and Rio de Janeiro were accompanied by the eyes of the chroniclers who wandered the streets registering their movements. Today, with the increasingly widespread access to social networks, ordinary citizens produce daily records of their surroundings, forming a visual map of their city. This article, through the creation of an Instagram profile called "Rio Recrio", investigates relationships that can be established between those chroniclers and users of the social network, taking as a scenario the urban transformations of Rio de Janeiro in the period known as Belle Époque and the contemporary.

Keywords: Narrative - City - Instagram - Chronicle - Metropolis - Literature.

[Las traducciones de los abstracts fueron supervisadas por el autor de cada artículo] 